\title{
Systems Thinking For Sustainable Design: A Conceptual Framework of Constructivist Web-Based Learning Environment Management Using Inquiry Learning Process
}

\author{
Sarinda Jamornmarn, Praweenya Suwannatthachote, Poonarat Pichayapaiboon \\ Faculty of Education, Chulalongkorn University, Bangkok, Thailand \\ Email: salwala@hotmail.com, praweenya@gmail.com,ppoonara@chula.ac.th
}

Received 2012

\begin{abstract}
This research is study sustainable education development on arts management, arranging the education with system approach which is operational method that emphasize on design, implementation and evaluation of overall process. The systematic thinking has holistic, interaction and networks characteristics. It has boundary and hierarchy of feedback-loops with system structure that has pattern and adaptation. The format of how to find the knowledge of systematic method is directly related to analysis, synthesis and operational plan. It is how to solve the problem by using scientific method. So the education must be inquiry-based instruction which consists of constructivist theory encouraging learners to create knowledge by themselves and learning environment on the networks which is a combination of constructivist learning system with media that has hyperlink, hypertext or hypermedia. The symbolic system of various media has influence to understanding or systematic thinking of learners while learning by technology that acts as learning environment for learners to create the knowledge by themselves. The researchers have realized the importance and study the development of Constructivist Web-Based Learning Environment Management Using Inquiry Learning Process to Enhance Systems Thinking for Sustainable Product Design of Undergraduate Students.
\end{abstract}

Keywords: Systems Thinking; Constructivist Web-Based Learning Environment; Sustainable Design; Inquiry Learning Process

\section{Introduction}

A concept of new development process has changed the development method by using "people" as center of the development especially support on education according to the meeting resolution of the United Nations at New York in December, 2002. It has the resolution for the year 2005-2014 to be United Nations Decade of Education for Sustainable Development (DESD) which says that "Education is the best hope of humanity in attaining the target of sustainable development".

Originally, a design would emphasize on designing to solve a problem and respond to the need of consumers which is to solve the problem on some points. It does not consider the whole but the sustainable development would choose resources that can be used again affecting environment the least and the attempt to connect people to environment by creating sustainable lifestyle and help to solve world's crisis in various ways. Therefore, sustainable development is considered as a perfect method in maintaining quality of life, designed to replace using of nonenvironment friendly product. We could say that this sustainable design is an important process of science and arts of all fields (Janis Biakeland, 2002) (Stuart Walker, 2006) (Carlos A. V. Costa, 2006)

The development of sustainable education in arts-related education management changes educational format emphasizing on creative thinking in solving a problem to be systematic thinking and holistic view in every related parts which is an important point of systematic thinking (Joanne Tippett, 2004) (Sandrine Simon, 2005) (Steve Turner, 2008).
The systems approach is directly related to analysis, synthesis and operation plan. It must be related to the operation method both on the inside and outside, using an open system and thinking foundation. It is a way that utilizes scientific method emphasizing on problems solving, understanding and specifying. Also, the method highlights on information collecting, choices developing, solution and stipulation in solving problems. Moreover, it evaluates each choice then chooses the best solution and evaluates the success of choice operation as well. Therefore, the arrangement of educational method must emphasize on inquiry-based instruction with scientific inquiry that is necessary for knowledge finding and studying. This discovery is systematic experiment to develop knowledge from creation of each person, influencing from original knowledge or experience and environment or social context according to constructivist theories. These theories encourage self-learning from inside thinking of learners as a creators of knowledge from the relationship with the incident and phenomenon as intellectual structure on self-knowledge creation theory. Self-knowledge creation theory is used for learning activity organizing for learners which encourage learners to create knowledge by themselves with appropriate learning environment, arranged by instructor. (Mark W. Aull \& Bruce M. Shore, 2008) (Biological Science Curriculum Study, 2006)

The constructivist learning management, characteristics and symbolic system of the media responding to self-creation knowledge is web-based learning environment which is the combination of constructivist theory and media with hyperlink, 
hypertext or hypermedia. The symbolic system of various media has influence to understanding or systematic thinking of learners while learning by using technology as learning environment in creating knowledge by themselves. Learners would act through their own thoughts and could find various answers (Sumalee Chaicharoen, 2008)

\section{The Theoretical Framework}

Researchers has emphasized on creation of framework, point of the inspection and analysis of document by using foundation from education and analyzing theory, research and variables. We connect the relationship between theory and this research, then conclude and use as foundation of the study.

\section{Concept 1. The Principle and Theory on Systematic Thinking}

The thinking method of system theory is the concept on the foundation of a complex system that has many possibilities. It considers relationship of various things that it related to. It is a thinking method that shows how to solve a problem systematically, emphasizing on considering at a problem as a whole. The format of knowledge finding is directly related to analysis, synthesis and operation method specification. It must be related to format on both inside and outside by using an open system as thinking foundation with the characteristics as follows (Kai Larsen, 2009) (Learning and people development Institute, 2003).(Bruce Mckenzie,2009) (Pornpan Poompu,2007) (Garry F. Hoban,2002) (Capra Fritjof,1997) (The Center for Ecoliteracy,2009) (Wattana Leungleu,2009) (Donella H. Meadows,2008) (Schoderbek,Peter P.and Others,1990)

1) Holistic thinking or wholeness: is an component of the situation or problem condition of work unit evaluation in the overall picture.

2) Networks thinking: is the interactive thinking with various systems composed as a network of thinking system with interaction between systems, minor systems and the large system with the environment.

3) Hierarchy thinking: is a system that may originate from the assemble of minor systems which relate to many parts of system component with boundary.

4) Feedback-Loops thinking: is thinking in loops rather than linear. Every part is connected directly and indirectly.

5) Pattern thinking: the system must be stable in order to be a principle so that every work process will not deviate from the overall target of the system. This is a thinking method with system structure. Each part has its individuality and independence but properly connects with each other and performs its function with other parts in order to achieve the overall system target.

6) Thinking with adaptation: the various systems will be adapted and tried to create and maintain that balance.

\section{Concept 2. The Principle and Theory Relating to Inquiry Learning Process}

7-step cycle learning management using metacognitive moves means one of learning processes that emphasizes on learners practice inquiry method by using metacognitive moves including intelligibility, plausibility and wide-applicability in teaching method so that learners can learn to think and develop their thinking at high level. Each step uses metacognitive moves to show the ability to think rationally and can evaluate one's own understanding. (Eisenkraft, 2003) (Bransford, Brown and Cocking, 2000)(Sumalee Chaicharoen, 2008).

1) Elicitation phase: is to establish a question in order to stimulate showing of original knowledge for teaching planning.

2) Engagement Phase: is a process of creating and developing overall thinking, process and skill by conducting survey and search, exchanging knowledge, inspection or gathering data on overall thinking which can connect to observation, differentiate variable and questions relating to the incident.

3) Exploration Phase: is planning and specifying a way to survey, inspect, set hypothesis, specify possibility and take action for information gathering or various phenomenon. The inspection method can be done by many means such as experiment, field activity, using computer to help create simulation and study data from reference and various sources

4) Explanation Phase: is to analyze, interpret, conclude data and propose the result in various forms such as conclusion, creating of model etc.

5) Expansion Phase/ Elaboration Phase: is to connect the created knowledge with the original knowledge or the concept that has been added, utilize the model or summary used in circumstance or other incidents explanation and help connect with the various stories and create wider feeling.

6) Evaluation Phase: is to evaluate the study by using various processes which lead to knowledge applying in other fields.

7) Extension Phase: is to prepare opportunity for students to implement the thing that they have learned to gain the highest benefit in daily life and use that knowledge to create the knowledge called "learning transfer".

\section{Concept 3. The Principle and Theory for Sustainable Design}

1) Evaluation of environmental impact: The evaluation of environmental impact is related to product or service. The main objective of environmental evaluation is to specify the part that has the most environmental impact in order to solve this problem for the entire design process.

2) Research: Product data includes rough details of product, function and important components, design and characteristics of production, history of product and development in the past, production and sources of all components, name list of material used in the product and production process. Important characteristics of products such as association usage, beauty and quality of product that is environmentally friendly

3) Operation on thinking operation: The operational work can be used to create systematic thinking and various strategies

4) Choosing design strategy: According to the foundation of all this information including environmental evaluation, analysis of general product and work operation review, design strategy can be chosen to find conclusion for the beginning of the design.

5) The actual design process: Regarding the various steps which include preparation of principle, design details, production of model, test and last step of the design after completing each step, this process would combine the evaluation from the beginning of the design including potential need, environmental objective, production point and cost.

\section{Concept 4. The Principle and Theory on Web-Based Constructivist Learning Environment}

Constructivist theory is a theory of active knowing which emphasizes on learning environments. Learning is active. It is a 
process that learners integrate new information with existing experience or original knowledge of learners. Learning environment and diverse concepts are valuable and necessary. Learners must create their own thinking. Learning is to create meaning from learners from the thing that learners see or hear which might be or might not be according to the objective of instructor. The created meaning from learners has greatly received the influence from original knowledge. So it can be concluded that according to constructivism theory, knowledge and learning would happen by oneself through interpreting the things in real world both object and event on the foundation of experience and knowledge that each person has to create meaning in the mind. Creating of meaning is continuous process and a person performs this process. In the learning situation, learners would establish a hypothesis, inspect and might change hypothesis while interacting with phenomenon with other people (Jaithip Na Songkhla, 2007; Sumalee Chaicharoen, (2008

Learning environment according to constructivist concept would use technology as a foundation to create interaction of learners with the meaning. The important thing is that learners would interpret and create meaning from experience and interaction with themself. Therefore, if students will apply this method they must adjust learning strategy to participate in that project with more meaning and activity that must encourage survey, test, creation, cooperation learning and result reflect after the study at the core of constructivist which is learners must do by themselves called "Active learner" or "student centered". The learning will encourage learners to have the most experience (Jonassen, .(1999

Jonassen (1999) has proposed the principle in designing learning environment which is called Constructivist Learning Environments (CLEs). The principle emphasizes on ability to solve a problem with complicated structure that highlight on learning from complicated problem, question or project. The problem or objective is from active learning. Learning from experience provides convenience for creating knowledge, exciting learning and emphasizing on reality.

CLEs principle has concept on arranging problematic environment project in various context. It is a force for learners who want to learn by arranging a case study relating to that problem so that learners can relate the knowledge from that sample and adjust it to a problematic condition. There is data source for learners to study and understand the problem and then propose the result that might happen and use cognitive tool to help learners interpret and act with the problem which would provide convenience to learners in solving a problem. Moreover, there is still cooperation tool to solve a problem that learners can communicate and help managing the structure of problem with meaning in order to create learning society and arrange for social supporting source that has condition of context in a real life. So that learners would learn with meaning and can be used in real life. The main features of the web-based constructivist learning environment are as follows:

1) Context: The context including

- Authentic Contexts: Maintain context in real life that has perfect situation from a viewpoint of designer who must arrange environment of learning center that give an opportunity to learners to reflect on thoughts or various viewpoints

- Authentic Activities: Give an opportunity to learners to search and find news source, related information. The characteristics of the said mission can integrate into different fields to reflect the complication and related characteristics, connection and relation (ill structure nature) with the problem that happens in real life.

2) Resource: It is a source for various materials that supports learning, starting from electronic media such as database, CAI and video to printing materials such as books, texts, general information, magazine, article and including people such as experts and a group of friend. While the media on the network, is a place that can gather diverse resource.

3) Tool: Processing Tool including

- Seeking Tool: helps inquiry and choose related information

- Collecting tool: learners gather sources according to their target. This tool will support by helping on collecting, gathering potential information which can be reached easily.

- Organization Tool: helps learners to propose relationship between various concepts.

- Integrating Tool: helps learners to connect new information with existing knowledge.

- Generation tool: would stimulate learners to create something for develop the design.

- Manipulation tool: is a tool that is used to test validity or survey the power of explanation in order to promote the adjustment of format structure used for understanding.

- Communication tool: would help encourage learners trying to be creative and exchange between learners, teachers and experts.

4) Scaffolding: It is the process which supported learning can segregate the difference by functional mechanism and the mechanical operational system which would emphasize on method or principle. The scaffolding would propose when the working system emphasize an objective, scaffolding format as follows

- Conceptual scaffolding: will be arranged from learners when a studying problem has been specified which is to externally impose or to bring into the context when a problem and scope has been specified. It might be possible to use a principle that has been learnt before as necessary thing in content scope wanted to study. To separate the knowledge, it is important that overall thinking relating to the problem or creating of structure by separating into important overall concept relating to a problem or structure, would be divided into categorization of overall concept

- Metacognitive Scaffolding: would help the process relating to knowledge management of each person. This scaffolding would manage the thinking concept during learning of metacognitive scaffolding. It might stimulate learners to reflect the target or connect to resource with the tool when the context is known and would deal with the problem or necessity in the operation of the problem.

- Procedural Scaffolding: is a way to use existing resource and tool that will be related to characteristics of system and operation. Moreover, it would give advice to learners during learning.

- Strategic Scaffolding: is a way that emphasizes on a method that might prove to be beneficial. Strategic Scaffolding would support analytical thinking, planning, strategy creating, decision-making. Strategy during an open learning would emphasize on the method to specify and choose information that needed to evaluate acquired resource and connect relationship with existing knowledge.

The learning method according to constructivist theory will not only help respond to contemporary learning and expand the learning scope everywhere but also help expand the educational 
opportunity from data source on the network and stimulate learners to communicate in society. Characteristics of multidimensional media can connect with other learning sources widely. It can find answers diversely to solve problems during learning with clear target and to learning on both time and nontime coordination by using resource and potential of the media in order to make learners learn with meaning through learning strategy of creating knowledge. Learning with meaning is important and technology will be used in coordination and support one another. In other words, technology is like context or environment for learning. Those environments would be supported from technology in a way of cognitive learning that enhances thinking of learners which would affect the learning of learner. Technology would support activity that would help learners to learn with meaning.

\section{Conclusion}

Management of the teaching of arts in university level has specified the necessity in producing a graduate who has skill in specific profession and can search knowledge by themselves continuously. The graduate should emphasize on design to solve market, social or environmental problem and be a designer who is responsible for society. However, in the arts council nowadays, it still lacks of clarity in this aspect. From that reason and importance, the study and enhancement of teaching method for sustainable development by using inquiry learning process according to the constructivist learning environment management in order to develop web-based systematic thinking skill in arts design work for students in bachelor degree level. It has to use learning process of student as a center to design a web-based learning environment that can be used as a medium to develop systematic thinking skill. This finding will lead to a development quality of student in Applied Art Design creating their work in a sustainable way.

\section{REFERENCES}

Biological Science Curriculum Study. 2006. The BSCS 5E Instructional Model : Origins and Effectiveness. [Online]. Available: URL : http://www.bscs.org/pdf/5EFull\%20Report.pdf (accessed December, 12.2009)

Bruce Mckenzie. 2009. Systemic Thinking. [Online]. Available: URL: http://www.systemics.com.au (accessed august, 20.2009)

Capra Fritjof. 1997. Web of Life: a new synthesis of mind and matter. London : Flamingo,

Carlos A. V. Costa. 2006. Education for sustainability: challenges and trends.Published online: 12 January 2006_ Springer-Verlag 2006

Civicnet Foundation. 2003. System Thinking. [Online]. Available: URL http://www.thaicivicnet.com/System\%20Thinking.htm) accessed June, 25.2009(

Donella H. Meadows. 2008. Thinking in System. Vermont : Chelsea
Green Publishing Co., 188 - 194

Biological Science Curriculum Study. 2006. The BSCS 5E Instructional Model : Origins and Effectiveness. [Online]. Available: URL : http://www.bscs.org/pdf/5EFull\%20Report.pdf (accessed December, 12.2009)

Bruce Mckenzie. 2009. Systemic Thinking. [Online]. Available: URL : http://www.systemics.com.au (accessed august, 20.2009)

Capra Fritjof. 1997. Web of Life: a new synthesis of mind and matter. London : Flamingo,

Carlos A. V. Costa. 2006. Education for sustainability: challenges and trends.Published online: 12 January 2006_Springer-Verlag 2006

Civicnet Foundation. 2003. System Thinking. [Online]. Available: URLhttp://www.thaicivicnet.com/System\%20Thinking.htm)accessed June, 25.2009

Donella H. Meadows. 2008. Thinking in System. Vermont : Chelsea Green Publishing Co., 188 - 194

Eisenkraft, A. 200. Expanding 5E model. Science Teacher, 70(6), 56-59.

Garry F. Hoban. 2002. Teacher Learning for Educational Change: A system thinking approach. Buckingham : Open University Press, 22-4

Jaitip Na Songkhla. 2007. E-Instructional Design. Bangkok: Texts and Documents Centre, Faculty of Education, Chulalongkorn University.

Janis Biakeland. 2002. Design for Sustainability. London : Earthscan Publication ltd,

Joanne Tippett. 2004. “Think Like an Ecosystem”Embedding a Living System Paradigm In to Participatory Planning. Systemic Practice and Action Research. Vol. 17, No. 6, December 2004 Springer Science+Business Media, Inc.

Kai Larsen, Claire McInerney, Corinne Nyquist, Also Santos and Donna Silbee. Learning Organizations. [Online]. Available from: http://home.nycap.rr.com/klarsen/learnorg/ (accessed June, 8.2009)

Mark W. Aull \& Bruce M. Shore.(2008).INQUIRY IN EDUCATION. New York: Tyler \& Francis Group,

Pornpan Poompu.2007.Systems Thinking. [Online]. Available: URL: http//www.kmcenter.rid.go.th/kcffd/.../Systems\%20Thinking\%201.d oc).accessed June, 25.2009

Sandrine Simon. 2005. Systemic Educational Approaches to Environmental Issues: The Contribution of Ecological Art.. Published online: 15 April 2006 C_Springer Science+Business Media, Inc.

Schoderbek,Peter P.and Othors .1990. Management System: Concetual Consideration. 4 .ed.,Richard D.Irwin,Inc.,6-10

Steve Turner. 2008. ASIT—a problem solving strategy for education and eco-friendly sustainable design. Published online: 6 November 2008_Springer Science+Business Media B.V.

Stuart Walker. 2006. Sustainable by Design: Explorations in Theory and Pratice. London : Gutenberg Press Ltd.,

The Center for Ecoliteracy . Principles of Ecology. [Online]. Available: URL:

http://www.ecoliteracy.org/pages/pri...ofecology.html(accessed July, 8.2009)

Sumalee Chaicharoen. 2008.Educational Teachnology: Principle Theories to Pratices. Khon Kaen: Klang na na wittaya Press Ltd.,

Wattana Leungleu 2009. System Thinking for HRD Professional [Online].Available:URL:http://123.242.160.129/aca2008/images/asemte mp/system\%20thinking.pdf (accessed November, 12.2009) 